\title{
Fotoproteção e Exercício Físico
}

\section{Photoprotection and Physical Exercise}

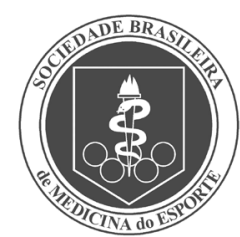

Artigo de Revisão
Kátia Sheylla Malta Purim

Neiva Leite ${ }^{2}$

1. Núcleo de Pesquisa em Qualidade de Vida (NQV) - Universidade Federal do Paraná - Curitiba Paraná.

2. Núcleo de Pesquisa em Qualidade de Vida (NQV) - Universidade Federal do Paraná - Curitiba Paraná.

\section{Endereço para correspondência:} Neiva Leite

Núcleo de Pesquisa em Qualidade de Vida. Departamento de Educação Física, Universidade Federal do Paraná (UFPR)

Rua Coração de Maria, 92 (BR-116, km 92) - 80215-370 - Jardim Botânico - Curitiba, PR, Brasil E-mail: neivaleite@gmail.com

\section{RESUMO}

As medidas de fotoproteção são divulgadas como procedimentos essenciais na prevenção de doenças cutâneas e manutenção da saúde e beleza. Os exercícios físicos regulares também são indicados para alcançar o estilo de vida saudável; no entanto, a prática esportiva expõe a maior radiação solar. O objetivo deste artigo é revisar as medidas fotoprotetoras na prevenção dos danos causados pelo Sol na pele dos desportistas. Abordam-se o histórico da fotoproteção, o espectro eletromagnético, os efeitos das radiações e os riscos de exposição durante as atividades físicas. Implementar estratégias, como a escolha do horário, local, roupas e acessórios, complementados pelo uso de filtros solares, minimizam os riscos decorrentes das radiações ultravioletas A e B (UVA e UVB) durante a prática esportiva ao ar livre. Dentre os produtos disponíveis no mercado, devem-se preferir aqueles que ofereçam segurança, ampla proteção, boa cosmética, estabilidade química em diferentes condições de calor e umidade, fotoestabilidade e baixo custo. O atleta deve ser orientado pelos profissionais da área da saúde sobre os riscos inerentes às suas atividades cotidianas e esportivas. O autoexame de pele é parte essencial na prevenção dos problemas dermatológicos, pois auxilia na detecção precoce. O futuro da fotoproteção no esporte está no investimento em medidas educativas desde a infância, reduzindo assim os danos solares cumulativos. A exposição solar deve ocorrer de modo cauteloso e com o mínimo de sequelas, mediante comportamento de fotoproteção, para proporcionar melhor qualidade de vida.

Palavras-chave: atividade física, radiações ultravioletas, fator de proteção solar, qualidade de vida, esportes.

\begin{abstract}
Photoprotection measures are reported as crucial procedures in the prevention of skin disorders and health and beauty maintenance. Although regular physical exercises are also recommended to attain a healthy lifestyle, sports activities expose one to increased sun radiation. The aim of this article is to review photoprotection measures as prevention for damage caused by the sun on the skin of athletes. The history of photoprotection, the effects of radiation and the risks of exposure during the practice of physical activities are reviewed. The implementation of strategies, such as selecting the time, place, clothing and accessories, in addition to the use of sunscreen, minimizes the risks resulting from ultraviolet A and B radiation (UVA and UVB) during sport's outdoor practice. Among the available products in the market, preference must be given to those that provide safety, wide protection, good cosmetics, chemical stability under various heat and humidity conditions, photostability, and low cost. The athlete must be guided by health professionals on the risks inherent to the everyday and sports activities. Skin self-examination is essential for the prevention of skin disorders as it helps in early detection. The future of photoprotection in sports lies on investment on educational measures from childhood, thus reducing the cumulative sun damages. Sun exposure must take place cautiously and with a minimum of sequela, through photoprotective behavior, in order to provide a better quality of life.
\end{abstract}

Keywords: physical activity, UV radiation, sun-protection factor (SPF), quality of life, sports. 


\section{INTRODUÇÃO}

Nas últimas décadas, o aquecimento global tem levado a maior preocupação quanto aos danos cumulativos das radiações ionizantes. As doenças causadas pelo Sol trazem impacto negativo sobre a qualidade de vida dos indivíduos, além de maiores gastos em saúde pública e na economia ${ }^{(1,2)}$

A pele humana possui diversos mecanismos de defesa contra as radiações solares, mas eles têm se mostrado insuficientes para uma proteção efetiva. A incidência de erupções cutâneas desencadeadas ou exacerbadas pelo Sol e, principalmente, o câncer de pele está aumentado em várias partes do mundo, inclusive no Brasil $^{(3-6)}$.

Existem indivíduos que apresentam predisposição ao desenvolvimento de doenças de pele, associados aos fatores genéticos e raciais, agravados pelo tempo e horário da exposição solar sem o uso adequado da fotoproteção. A prática de exercícios físicos pode ser fator para o desenvolvimento de problemas cutâneos, visto que o treinamento exige muitas horas de atividades ao ar livre ${ }^{(7)-9)}$.

O potencial genético para o desempenho em modalidades esportivas de resistência está associado a maior proporção de fibras musculares do tipo I, geralmente presente em indivíduos caucasianos ${ }^{(10)}$, fototipo com maior risco de carcinogênese ${ }^{(11)}$. Além disso, as atividades de longa duração sofrem os efeitos da exposição cumulativa a radiação ultravioleta e da imunossupressão causada pelo excesso de treinamento(12,13).

Embora muitas investigações demonstrem os riscos da radiação solar, ainda hoje há carência de pesquisas nesta área nos desportos e atividades físicas. $\mathrm{O}$ atleta expõe muitas áreas desprotegidas do seu corpo ao meio ambiente podendo ser um candidato potencial as suas consequências ${ }^{(8,14)}$.

O objetivo deste artigo é revisar as medidas fotoprotetoras na prevenção dos danos causados pelo Sol na pele dos desportistas. Abordam-se o histórico da fotoproteção, o espectro eletromagnético, os efeitos das radiações e os riscos de exposição durante a prática de atividades físicas.

\section{Histórico da fotoproteção: o primórdio e o presente}

O bronzeamento da pele tem diferentes representações socioculturais no decorrer dos séculos. Antes da Revolução Industrial, o escurecimento cutâneo era associado ao trabalho agropastoril e a pele de tonalidade branca, como a porcelana, a uma classe social mais elevada. Com o advento das fábricas, os operários que permaneciam mais tempo em ambientes fechados tendiam ao clareamento da cútis. As classes sociais privilegiadas passaram a desenvolver diversas práticas de lazer e atividades ao ar livre, e a cor bronzeada foi relacionada à melhor qualidade de vida(15).

O excesso de exposição solar trouxe efeitos deletérios imediatos como as queimaduras solares. Durante a Guerra do Vietnã, o exército americano passou a estimular o uso de pastas na face dos seus soldados na tentativa de minimizar eritema e bolhas. Mas, somente nos tempos modernos, foi comprovado ser necessária e aconselhável a utilização de recursos físicos ou químicos de proteção cutânea. A era dos fotoprotetores iniciou na década de 30 através da utilização de produtos contendo salicilatos ${ }^{(16)}$.

Apesar do surgimento das medidas farmacêuticas de fotoproteção e dos esforços para reduzir a exposição ao Sol, a valorização social do bronzeamento, com significado de status e beleza, não estimulou a proteção cutânea adequada ${ }^{(17-20)}$

Nos últimos anos, houve maior prejuízo à saúde em função da redução na camada de ozônio, impulsionando avanços na informação científica e inovações tecnológicas promissoras. 0 desenvolvimento dos cosméticos e a exigência por produtos cada vez mais efetivos para atenuar os efeitos da radiação nos diferentes tipos de pele, pro- porcionaram maior acesso e crescimento na utilização de fotoprotetores em todo o mundo, com o intuito de reduzir efeitos deletérios da exposição excessiva. A participação esportiva em atividades ao ar livre durante treinos e competições expõe os indivíduos a maiores riscos de exposição às radiações eletromagnéticas, que serão descritas no próximo tópico.

\section{Espectro eletromagnético}

A radiação solar compreende todo o espectro eletromagnético resultante da distribuição de energia em uma onda de luz. A luz é constituída por campos elétricos e magnéticos que se propagam em velocidade constante no vácuo. As principais características da luz são o comprimento e a frequência de onda, que são inversamente relacionados, ou seja, quanto maior o comprimento de onda menor a frequência(21).

O espectro eletromagnético é extremamente amplo e tem comprimentos de onda desde o raio gama ( $10^{-24}$ metros) até as ondas de rádio (107 metros). As faixas de comprimento de onda de interesse médico são: o ultravioleta (UV), a luz visível e o infravermelho (IV).

Radiação ultravioleta: A radiação ultravioleta (UV) apresenta comprimentos de onda de 100 a 400 nanômetros (nm) sendo dividida em três faixas: A, B e C.

Radiação ultravioleta $\mathbf{A}$ (UVA): a faixa de comprimento de onda é de 320-400nm e atravessa a maior parte dos vidros comuns. A radiação UVA é subdividida em UVA baixa (320-340nm) responsável pela grande maioria dos efeitos fisiológicos na pele e UVA alta (340-400nm) que causa alterações nas estruturas dérmicas. A UVA exerce ação direta sobre os vasos da derme, determinando vasodilatação e eritema gradual. Nas células epidérmicas, promove quebra das cadeias do DNA que, posteriormente, sofre reparos por mecanismos enzimáticos. Dependendo da espessura da pele e do tempo de exposição solar, a UVA pode causar: pigmentação imediata e tardia, envelhecimento cutâneo, carcinogênese, desencadeamento de doenças como lúpus eritematoso, erupção polimorfa à luz e fotoalergias ${ }^{(21,22)}$.

Radiação ultravioleta B (UVB): a faixa de comprimento de onda é de 290-320nm. A UVB é absorvida pelo vidro comum. Apesar da pequena penetração na pele, sua alta energia é responsável pelos danos solares imediatos e boa parte dos danos tardios. Por ação do UVB há lesão de células epiteliais com formação de substâncias vasodilatadoras, como as prostaglandinas. A UVB participa do metabolismo epidérmico da vitamina D, mas pode causar: eritema, pigmentação tardia, espessamento da epiderme e carcinogênese ${ }^{(21-23)}$.

Radiação ultravioleta C (UVC): a faixa de comprimento de onda é de 100-290nm. A UVC é absorvida pelas camadas superiores da atmosfera terrestre rica em ozônio. Praticamente não chega à superfície terrestre. Estudos recentes apontam diminuição da camada de ozônio cujas consequências ainda não estão totalmente esclarecidas, mas já afetam a vida e o planeta(21,22).

Luz visível: a luz visível situa-se entre 400 e 700nm, excita a retina com a formação de imagens pela absorção da radiação pela rodopsina possibilitando ao cérebro a distinção de cores (violeta, azul, verde, amarelo, alaranjado e vermelho). Um fóton de UV possui mais energia do que o fóton da luz visível e da radiação IV, podendo contribuir para o desenvolvimento de doenças cutâneas e oculares ${ }^{(24)}$

Radiação infravermelha (IV): A radiação infravermelha (IV) representa cerca de 50\% do espectro solar, possui frequências menores e gera pouca energia. É responsável pelo transporte do calor do Sol para a Terra sendo chamada faixa de raios calóricos. Penetra até a hipoderme provocando aumento de temperatura, calor e vasodilatação cutânea. Parece exercer efeito aditivo a radiação ultravioleta, contribuindo com o envelhecimento e carcinogênese. 
A intensidade da radiação bem como o comprimento de onda da luz solar depende da altitude, latitude, estação do ano, condições atmosféricas e hora do dia. Em geral, é mais lesiva das 10:00h às 14:00h, quando atravessa menor faixa de ozônio, e contêm maior quantidade de radiação ultravioleta $\mathrm{B}^{(2,4)}$.

A consciência da preservação ambiental tem conduzido à busca de soluções para o desenvolvimento sustentável. Dentro desta ótica, a energia solar se constitui em fonte de geração de eletricidade, calor e produção de combustível. Tem sido utilizada em sistemas de aquecimento de água residencial, em repetidores de telecomunicações, bem como, fornecimento de energia elétrica para equipamentos e dispositivos espaciais. Pesquisas estão sendo realizadas para melhor aproveitamento da energia solar, com enorme potencial de aplicação em larga escala ${ }^{(25)}$.

\section{Efeitos das radiações no organismo}

O ciclo claro-escuro é o mais importante fator ambiental sincronizador dos ritmos biológicos. O ritmo circadiano faz parte da vida e pode ser encontrado virtualmente em todas as plantas e animais, incluindo o homem. A informação da claridade é transmitida da retina ocular para o núcleo supraquiasmático e deste para a glândula pineal que regula a secreção de melatonina ${ }^{(26)}$.

A representação interna do dia e da noite envolve três componentes: um oscilador interno (endógeno) localizado no núcleo supraquiasmático; osciladores externos (exógenos) que têm a função de sincronizar o oscilador interno; e a melatonina, um hormônio que é suprimido na presença da luz, aumentando até um determinado platô durante o sono e diminuindo novamente com o despertar ${ }^{(26,27)}$.

A luz natural produz efeitos biológicos e psicológicos no organismo humano. Tem sido associada com a maior produtividade, menor absenteísmo e menor índice de erros no trabalho. Pesquisas apontam que a luz natural estimula atitudes positivas, reduz a fadiga e diminui problemas de visão(28)

O corpo humano usa a luz como nutriente para os processos metabólicos similarmente à água ou alimentos. A luz natural auxilia as funções biológicas cerebrais. Em dias nublados ou em condições de pouca luminosidade, a dificuldade de perceber as cores pode afetar o humor e os níveis de energia. Estudos recentes comprovam a eficácia da luz natural na redução da depressão em pacientes com transtornos $\operatorname{afetivos}^{(28,29)}$

Na ausência da luz e de outros marcos externos, o oscilador interno continua a operar, mas com um período mais longo do que as 24 horas do dia. Estímulos externos são necessários para sincronizar o oscilador interno no período de 24 horas, bem como o ajuste das estações do ano. A alternância claro-escuro entre o dia e a noite é um dos mais importantes estímulos externos usados para a sincronia. Este sistema é importante para a autorregulação corporal. Influencia as atividades biológicas como a produção de hormônios, a alimentação, os estados de vigília e sono(30) assumindo grande importância para os atletas, principalmente em períodos de campeonatos $^{(26)}$.

\section{Efeitos das radiações na pele}

A luz que incide sobre a pele pode ser absorvida, refletida ou espalhada. Apenas a luz absorvida produz alterações na molécula que a absorve dita cromóforo, entre os quais estão os ácidos nucleicos (formam o DNA) e os aminoácidos (formam proteínas). Cada cromóforo absorve a luz numa determinada faixa de comprimento de ondas sofrendo reações fotoquímicas ou fotobiológicas, dependendo da intensidade da luz, arranjo molecular e outros fatores como o fototipo ${ }^{(21)}$.

As peles foram classificadas segundo Fitzpatrick em seis fototipos de acordo com a sensibilidade pigmentar à luz ultravioleta, fornecendo indicações acerca da origem étnica ${ }^{(31)}$. No Brasil esta classificação foi adaptada à miscigenação de raças existentes, sendo considerada como população negra a soma de pardos e pretos ${ }^{(2,4,32)}$.

A identificação do fototipo é útil para apontar quais atletas apresentarão alto risco de alterações decorrentes do Sol. Os indivíduos de pele clara reagem com maior intensidade a menores doses de radiação ultravioleta do que os de pele escura. O maior conteúdo de melanina e o padrão de dispersão dos melanossomas dos indivíduos negros são fatores de proteção para o envelhecimento cutâneo, as fotodermatoses e os efeitos carcinogênicos da luz solar ${ }^{(32)}$.

Os distúrbios cutâneos dependem do tipo de pele e tempo de exposição solar, em conjunto com as características raciais e imunogenéticas ${ }^{(33,34)}$, resultando em diferentes graus de sensibilidade, sumarizados no quadro 1.

Dentro destas distintas tonalidades de pele correspondem ainda diversas capacidades de suportar os raios solares, as pessoas com maior sensibilidade da pele apresentam maior risco de queimadura solar quando comparados àquelas de menor sensibilidade ${ }^{(35)}$.

O espectro ultravioleta da radiação é usado no tratamento de distúrbios cutâneos como vitiligo, psoríase e eczemas ${ }^{(2)}$. A exposição à radiação e à luz parece conferir benefícios psicológicos, como o efeito antidepressivo. Auxilia no metabolismo da vitamina D necessária a prevenção de osteoporose muito embora, verifique-se para indivíduos com deficiência de vitamina $D$, tendência de recomendar uma dieta adequada ou suplemento vitamínico ${ }^{(36)}$.

As manifestações deletérias e cumulativas das radiações causam sérios problemas ao sistema tegumentar em todos os indivíduos. Entretanto, alguns organismos estão mais sujeitos e susceptíveis que outros aos riscos de: queimadura, pigmentação, fotoenvelhecimento, lesões cutâneas e carcinogênese $e^{(4,18,37,38)}$.

Quadro 1. Tipos de pele quanto a resposta ao Sol.

\begin{tabular}{|c|l|l|l|l|}
\hline $\begin{array}{c}\text { Fototipo segundo } \\
\text { Fitzpatrick }\end{array}$ & \multicolumn{1}{|c|}{ Cor da pele } & \multicolumn{1}{|c|}{ Resposta ao Sol } & \multicolumn{1}{|c|}{ Sensibilidade } & Principais representantes \\
\hline I & Branca clara & Sempre queima, nunca pigmenta & MUITO SENSÍVEL & Albinos e ruivos \\
\hline$\|$ & Branca & Sempre queima, pigmenta pouco & MUITO SENSÍVEL & Loiros \\
\hline III & Branca a morena-clara & Queima e pigmenta moderadamente & SENSÍVEL & Brancos \\
\hline IV & Morena-escura & Queima pouco, sempre pigmenta & POUCO SENSÍVEL & Morenos e latinos \\
\hline V & Parda & Raramente queima, sempre pigmenta & POUQUÍSSIMO SENSÍVEL & Árabes, mediterrâneos, mestiçOS, asiáticos \\
\hline VI & Preta & Nunca queima, sempre pigmenta & MENOS SENSÍVEL & Negros \\
\hline
\end{tabular}

Adaptado de Sampaio, 2007 


\section{Exercícios físicos e radiações solares}

As atividades físicas ao ar livre expõem os praticantes a distúrbios cutâneos agudos e crônicos. Durante o exercício físico, o organismo pode sofrer agressões de variados modos, origens, frequências e intensidade. A atividade ao ar livre é frequentemente sujeita à ação de luz solar, picada de insetos, contato com vegetais, exposição à chuva e ventos, ao frio, ao calor, ao solo, produtos químicos, bem como, à ação de outros agentes que podem ser potencialmente perigosos para a pele. Em geral, os locais mais vulneráveis e de maior exposição direta ao meio ambiente são a face, o pescoço, a área superior do tórax (" $\vee$ " do decote), os dorsos das mãos e os braços.

Especial atenção deve ser direcionada às crianças e adolescentes que, ao longo da vida, estarão acumulando radiação, tanto por exposição solar ocasional, dentro de carros e nos percursos do dia a dia, quanto por exposição intencional nas atividades recreativas e desportivas ao ar livre ${ }^{(18,39)}$.

Atletas de elite submetem-se a meses de treinamento e preparação física podendo sofrer diferentes alterações na pele relacionadas ao esporte. Dependendo da modalidade esportiva e da duração de atividades ao ar livre, ocorre maior exposição à radiação solar. Lesões cutâneas precisam ser reconhecidas, tratadas e prevenidas para evitar comprometimento à participação e desempenho nas competições ${ }^{(7,40,41)}$

Ocasionalmente, outras dermatoses podem ser fotorreativas como o herpes simples labial, o eritema multiforme, o pênfigo eritematoso e as erupções medicamentosas $(2,11,13,34)$.

Entretanto, poucos estudos referem a prevalência destes danos por exposição solar em atletas $(7,8,40,41)$. Pesquisas recentes apontam que a incidência de carcinoma basocelular e espinocelular é maior em trabalhadores de pele clara expostos à luz solar ${ }^{(11,34)}$. Em atletas que permanecem mais tempo ao Sol, como, por exemplo, os maratonistas, observa-se maior risco do desenvolvimento de melanoma ${ }^{(42)}$.

As atividades esportivas estão passando por modificações nas suas características e práticas. Nos últimos anos ocorreu incremento da participação de populações especiais, como gestantes, idosos e para-atletas. Verifica-se, em especial, o crescimento de adeptos de corridas de rua, desportistas de finais de semana e de esportes de aventuras. $O$ aumento de praticantes de exercícios físicos em nível de treinamento ou em busca de qualidade de vida acarreta na necessidade de fotoproteção mais efetiva, o que será abordado no próximo tópico.

\section{FOTOPROTEÇÃO E EXERCÍCIO FÍSICO}

A fotoproteção pode ser entendida como um conjunto de medidas para reduzir ou atenuar a exposição às radiações solares, visando prevenir consequências deletérias das mesmas. Os fotoprotetores, conhecidos como filtros solares, são produtos destinados a proteger a pele, lábios e cabelos das radiações ultravioletas através de ações químicas, físicas ou biológicas. Atualmente, são comercializados em forma de creme, loção, gel, pasta, bastão labial, spray, xampu, condicionador capilar e outros veículos que agem por mecanismos físicos e químicos, isolados ou combinados.

Na prática de exercícios físicos devem ser observadas algumas características destacadas a seguir:

\section{Horário e locais de treinamento}

A escolha adequada do horário de exposição ao ar livre é fundamental para minimizar danos e agravos provocados pela radiação. Devem-se programar os treinos para o início da manhã e principalmente para o final da tarde quando a incidência das radiações começa a declinar ${ }^{(43,44)}$. Além disso, deve-se verificar a altitude do local de treinamento em função da menor ou maior intensidade das radiações.
A radiação solar incidente no limite superior da atmosfera sofre uma série de reflexões, dispersões e absorções durante o seu percurso até o solo. Sua disponibilidade varia conforme o local, época do ano e alterações climáticas, sejam diurnas, sazonais ou anuais. A variação diurna é função do movimento de rotação da Terra, a sazonal é função da inclinação do eixo, enquanto que a anual é função da órbita elíptica da Terra em torno do Sol. Outras variações significativas são previstas por estatística, tal como a incidência média da radiação solar por um período de tempo. Existem ainda os efeitos da formação de nuvens, poluição atmosférica, pó e nevoeiros ${ }^{(4,25)}$.

A incidência total de radiação solar sobre um corpo localizado no solo é a soma destes múltiplos componentes. Em condições de céu claro e ausência de nuvens, a radiação máxima observada ao meiodia em local situado ao nível do mar é de $1 \mathrm{~kW} / \mathrm{m}^{2}$. A 1.000 metros de altura, a radiação é de $1,05 \mathrm{~kW} / \mathrm{m}^{2}$. O Brasil apresenta alto índice de radiação solar, principalmente no Nordeste, onde possui valores entre $1.752 \mathrm{~kW} / \mathrm{m}^{2}$ a $2.190 \mathrm{~kW} / \mathrm{m}^{2}$ por ano. Para comparação, o deserto do Saara recebe em torno de $2.600 \mathrm{~kW} / \mathrm{m}$ por ano ${ }^{(25)}$.

A prática esportiva em dias nublados deve ser cuidadosa, porque grande percentual dos raios UV atravessa as nuvens ${ }^{(45)}$. Os maratonistas, os ciclistas e os triatletas estão sujeitos às queimaduras solares, porque há maior área corporal desprotegida e tempo de exposição durante os treinamentos e competições ${ }^{(46)}$.

\section{Uniforme e equipamentos esportivos}

As vestimentas e os complementos do uniforme esportivo são amplamente empregados para a segurança do atleta no exercício de suas funções. A indústria têxtil tem fabricado produtos cada vez mais sofisticados, resistentes, práticos e de fácil manutenção, destinados a proteger a integridade física e a saúde ${ }^{(47)}$

Recentemente, estão sendo desenvolvidos tecidos de algodão e viscose com capacidade de retenção da luz ultravioleta (UV). Testes in vitro, por meio de espectrofotometria, e in vivo, por meio da dose eritematosa mínima (DEM) com e sem tecido, apontam bons índices de proteção. A cor do vestuário e o uso de detergentes e produtos derivados da triazina, que absorve a radiação UV, podem aumentar a capacidade de proteção em até quatro vezes ${ }^{(48,49)}$.

A unidade fator de proteção (UFP) é utilizada pelos fabricantes para medir a proteção que o tecido específico confere à pele contra a emissão de luz UVA e UVB. Os resultados têm mostrado a seguinte tendência: boa proteção (UFP de 15 a 24), muito boa (UFP de 25 a 39) e excelente (UFP de 40 a 50). Isto pode ser entendido da seguinte forma: um vestuário com fator de proteção 50 significa que apenas 1/50 da luz ultravioleta penetra pelo tecido, ou seja, 2\% dos raios conseguem atravessar o tecido e atingir a pele(48).

À medida em que o tecido envelhece e recebe lavagens sucessivas, o poder de proteção diminui. Branqueadores óticos e agentes químicos apropriados parecem manter a capacidade protetora. Recursos da nanotecnologia podem ser promissores e o aperfeiçoamento destes tecidos contribuirá também para a melhor proteção do atleta ${ }^{(49)}$.

Acessórios como as meias absorvem o suor e bloqueiam a radiação solar. Chapéus com abas largas são inadequados para esportes de resistência, mas pode-se usar boné para proteção da fronte e da face. Os capacetes dos ciclistas oferecem proteção contra Sol e traumas. Já o uso de óculos específicos para determinadas atividades protege as pálpebras e é permitido, por exemplo, em esportes praticados na neve.

\section{Recursos fotoprotetores}

As substâncias permitidas para uso como protetores solares no Brasil constam em resolução específica da Agência Nacional de Vigilância Sanitária (Anvisa). Para cumprir sua função com eficácia e segurança, o 
filtro deve possuir as seguintes características: absorver a radiação na faixa de 280-400nm, ter baixa solubilidade em água, ser atóxico, não-irritante, não-sensibilizante, ter baixo preço e boa aceitação cosmética(50).

O veículo utilizado para o filtro solar influencia no fator de proteção, pois a boa espalhabilidade e aplicabilidade sobre a pele auxiliam ou não a formar um filme uniforme e homogêneo. Deve ser compatível com o tipo específico de pele e o local da aplicação.

Nos cabelos ou áreas pilosas indicam-se filtros incorporados em xampus, condicionadores, soluções capilares ou sprays. Para peles ressecadas, preferir cremes, loções ou fluidos. Peles oleosas toleram melhor os géis, enquanto que as áreas de lábios requerem bastões próprios para mucosas.

O filtro solar é, erroneamente, uma das primeiras alternativas usadas na prevenção e o seu uso inadequado pode gerar falsa sensação protetora. Pesquisas mostram que o protetor solar não protegeu o usuário em 55\% das vezes. Em condições de trabalhos ao ar livre, caso ocorra sudorese profusa, torna-se necessária nova aplicação nas áreas expostas à luz duas a três horas após a primeira aplicação(51).

Pesquisas recentes apontam para o desenvolvimento de filtros mais eficazes, biocompatíveis e com melhor comodidade de uso. Provavelmente, ocorrerá substituição dos sistemas FPS e desenvolvimento de novos ativos, inclusive de uso sistêmico ${ }^{(1,2,52,53)}$.

O filtro solar físico proporciona proteção através do efeito de cobertura sobre a pele. No seu mecanismo de ação verifica-se que não ocorre interação entre o fóton e a partícula do filtro. Os representantes deste grupo são: óxido de zinco, talco, caulim e dióxido de titânio. Podem ser recomendados para todos os tipos de pele, sendo especialmente utilizados nos produtos destinados ao público infantil e desportos aquáticos. Em geral, são substâncias refletoras opacas que protegem contra a luz visível e as radiações ultravioletas A e B. Entretanto, podem ser cosmeticamente pouco aceitáveis ${ }^{(2,21)}$.

O filtro solar químico proporciona proteção parcial ou total na radiação UVA e UVB através de substâncias naturais ou sintéticas. A molécula de um filtro solar químico ao receber energia da radiação ultravioleta sai do estado fundamental indo para o estado excitado, retornando ao estado fundamental após dissipar esta energia. Geralmente, os filtros químicos possuem moléculas com duas porções: cromófora e auxocrômica. A porção cromófora é capaz de absorver radiações de determinado tipo de onda. A porção auxocrômica modifica a capacidade de absorção do componente cromóforo. Os fotoprotetores com PABA apesar de causar dermatites, possuem resistência parcial à sua remoção pelo suor e imersão em água. Absorvem radiação UVB no espectro 280-320nm conferindo FPS de 10 a 15 (2,21).

Além destes filtros orgânicos e inorgânicos, existem ativos capazes de interferir em outros estágios do processo de fotodano. São considerados adjuvantes dos filtros solares, entre os quais destacam-se os antioxidantes (vitaminas C e E) e os agentes anti-inflamatórios (isoflavonas e polifenóis). Novos produtos estão sendo investigados para minimizar os danos celulares ocasionados pelas radiações solares.

Como ainda não existe um filtro ideal dentre os produtos disponíveis no mercado, deve-se preferir aqueles que ofereçam segurança, ampla proteção, boa cosmética, estabilidade química em diferentes condições de calor e umidade, fotoestabilidade e baixo custo. Estudos enfatizam, principalmente, a importância da conscientização sobre os perigos da exposição excessiva ao Sol(54).

\section{Autoexame de pele}

O autoexame de pele é parte essencial na prevenção dos problemas dermatológicos, pois auxilia na detecção precoce. O indivíduo deve ser encorajado a examinar mensalmente toda a superfície cutânea incluindo couro cabeludo e as áreas normalmente não expostas como axilas, ná- degas, genitais e pés. Esta atitude é particularmente importante e recomendável para parentes de primeiro grau de pacientes com histórico de câncer de pele, bem como indivíduos com os fototipos I, II e III, e ainda, para os portadores de lesões pré-malignas induzidas pelo Sol ${ }^{(17,38)}$.

Provavelmente, atletas desprotegidos, ou mal protegidos, da radiação solar podem reagir com eritemas repetidos nas áreas fotoexpostas, o que, com o passar dos anos, podem determinar o aparecimento de lesões benignas, pré-malignas e malignas. Portanto, estes indivíduos precisam ser treinados a combater os fatores de risco para doenças cutâneas. Caso apresentem alguma alteração, devem ser monitorizados por médicos.

É importante ressaltar que a proteção solar absoluta é difícil. Uma parcela da radiação irá atravessar a pele e se acumular nas células. A motivação do atleta e a ação conjunta da equipe de saúde do esporte são de suma importância para minimizar danos e agravos, bem como mobilizar treinamentos e recursos voltados à melhoria da qualidade da assistência técnica e humana no esporte, nos diferentes cenários de atuação dos atletas.

\section{Recomendações principais no esporte}

Todos os atletas devem conhecer fatos básicos sobre a proteção solar:

1) O dano solar é cumulativo.

2) O bronzeamento é a resposta ao dano cutâneo provocado pelos raios UV.

3) Evite exposição solar entre 10 e 14 horas. Planeje atividades para o início da manhã ou, preferencialmente, no final da tarde.

4) Proteja a pele com roupas e equipamentos adequados.

5) Use corretamente protetores solares de amplo espectro.

\section{Perspectivas futuras}

A energia solar é uma excelente fonte de eletricidade renovável e vem sendo eleita nos países desenvolvidos como alternativa energética. Os danos causados pela utilização deste recurso natural podem ser minimizados por estudos de proteção ambiental com embasamento científico e maior engajamento da população em geral nas ações preventivas.

A propagação dos riscos da exposição solar pela mídia vem aumentando a consciência do problema, despertando iniciativas de prevenção primária na infância ${ }^{(6,39)}$. O futuro da fotoproteção no esporte está no investimento em medidas educativas desde as categorias infanto-juvenis, evitando assim a exposição solar cumulativa ${ }^{(44,56)}$. Cuidados básicos serão cada vez mais divulgados e incorporados, entre eles: evitar, bloquear e cobrir a pele dos efeitos da radiação. Novos hábitos em relação ao Sol precisam ser adquiridos pelos atletas, gerando mudança de paradigmas, a fim de minimizar a exposição solar desprotegida.

Assim sendo, o ganho deste artigo relaciona-se à sua condição de aplicar os conhecimentos iniciais dessa natureza, habilitando-se a promover a continuidade de publicações sobre a pele e o esporte para compor um acervo mais aprofundado e esclarecedor sobre a fotoproteção do atleta brasileiro.

\section{CONCLUSÃO}

A exposição solar pode acarretar benefícios físicos e psicológicos ao desportista. No entanto, utilizada de maneira equivocada ou desprovida de proteção, pode alterar negativamente a pele, prejudicando a saúde. $O$ atleta deve ser orientado sobre os riscos inerentes às suas atividades cotidianas e esportivas. A exposição solar deve ocorrer de modo cauteloso e com o mínimo de sequelas, mediante fotoproteção, para proporcionar melhor qualidade de vida.

Todos os autores declararam não haver qualquer potencial conflito de interesses referente a este artigo. 


\section{REFERÊNCIAS}

1. Brasil. Ministério da Saúde. Secretaria de Atenção a Saúde. Departamento de Ações Programáticas Estratégicas. Dermatoses Ocupacionais/ Ministério da Saúde. Secretaria de Atenção a Saúde. Departamento de Ações Programáticas Estratégicas. Brasília:Editora do Ministério da Saúde, 2006, 92 p.

2. Sampaio SAP, Rivitti EA. Dermatologia. São Paulo: Artes Médicas, 3a Edição, 2007.

3. Diepgen TL, Mahler V. The epidemiology of skin cancer. Br J Dermatol 2002;146:1-6.

4. Nasser N. Epidemiologia dos carcinomas basocelulares em Blumenau, SC, Brasil, de 1980 a 1999. An Bras Dermatol 2005;80:363-8.

5. BRASIL. Ministério da Saúde. Secretaria de Atenção à Saúde. Instituto Nacional do Câncer. Coordenação de Prevenção e Vigilância de Câncer. Estimativa 2008: Incidência de câncer no Brasil, 2008.

6. Sociedade Brasileira de Dermatologia. Análise de dados das campanhas de prevenção ao câncer da pele promovidas pela Sociedade Brasileira de Dermatologia de 1999 a 2005. Anais Bras Dermatol 2006;81:533-9.

7. Adams BB. Dermatologic disorders of the athlete. Sports Medicine 2002;5:309-21.

8. Adams BB. Sports Dermatology. New York: Springer, 2006

9. Bakos RM, Wagner MB, Bakos L, De Rose, EH, Granjeiro Neto JÁ. Queimaduras e hábitos solares em um grupo de atletas brasileiros. Rev Bras Med Esporte 2006;12:275-8.

10. Ama PF, Simoneau JA, Boulay MR, Serresse O, Theriault G, Bouchard C. Skeletal muscle characteristics in sedentary black and Caucasian males. J Appl Physiology 1986;61:1758-61.

11. Harris RB, Griffith K, Monn TE. Trends in incidence of nonmelanoma skin cancer in southeastern Arizona, 1985-1996. J A Acad Dermatol 2001:45:528-36.

12. Wiggs WP. Playing it safe in the sun: primary prevention of skin cancer for sun-exposed athletes. Dermatol Nurs 2007;19:555-60.

13. Wang SQ, Settlow R, Berwick M. Ultraviolet A and melanoma: a review. J Am Acad Dermatol 2001;45:837-46.

14. Noble-Jerks J, Weatherby RP, Meir R. Self-reported skin cancer protection strategies and location of skin cancer in retired cricketers: A case study from membership of the Emu Cricket Club. J Sci Med Sport 2006;9:441-5.

15. Randle HW. Suntanning: differences in perceptios throughout history. Mayo Clin Proc 1997;72:461-6

16. Martins JEC, Paschoal LHC. Dermatologia terapêutica. $4^{\circ}$ ed. Rio de Janeiro: Dilivros, 2006.

17. Stern RS. Treatment oh photoaging. N Engl J Med 2004;350:1526-34.

18. Benvenuto-Andrade C, Zen B, Fonseca G, De Villa D, Cestari T. Sun exposure and sun protection habits among high-school adolescents in Porto Alegre, Brazil. Photochem Photobiol 2005;81:630-5.

19. Thieden E, Philiphsen PA, Sandby-Moller J, Wulf HC. Sunscreen use related to UV exposure, age, sex and occupation based on personal dosimeter readings and sun-exposure behavior diaries. Arch Dermatol 2005;141:967-73.

20. Cokkinides V, Weinstock M, Glanz K, Albano J, Ward E, Thun M. Trends in sunburns, sun protection pratices, and attiudes toward sun exposure protection and tanning among US adolescents, 19982004. Pediatrics 2006;118:853-64.

21. Matheus LGM, Kurebayashi AK. Fotoproteção: a radiação ultravioleta e sua influência na pele e cabelos. São Paulo: ABC - Associação Brasileira de Cosmetologia, 2002.

22. Flor J, Davolos MR, Correa MA. Protetores solares. Quím Nova 2007:30:1-10.

23. Okuno E, Vilela MAC. Radiação ultravioleta: características e efeitos. Temas atuais de física. Editora Livraria da Física. Sociedade Brasileira de Física. São Paulo, $1^{\circ}$ edição, 2005.

24. Oliveira GF; Campos LRC, Temporal WF. Efeito das radiações ultravioletas nas atividades aéreas e terrestres. RMAB 2005;55:19-26.

25. Albadó R. Energia solar. São Paulo: Artliber Editora, p. 9-11, 155p, 2002

26. Back FA, Fortes FS, Santos EHR, Tambelli R, Menna-Barreto LS, Louzada FM. Sincronização não-fótica: o efeito do exercício físico aeróbio. Rev Bras Med Esporte 2008;13:138-42.

27. Martinez D, Lenz MCS, Luiz Menna-Barreto L. Diagnóstico dos transtornos do sono relacionados ao ritmo circadiano. J Bras Pneumol 2008:34:173-80.

28. Edwards L, Torcellini P. A Literature Review of the Effects of Natural Light on Building Occupants NREL/ TP-550-30769 National Renewable Energy Laborator July 2002.
29. Juruena MF; Cleare AJ. Superposição entre depressão atípica, doença afetiva sazonal e síndrome da fadiga crônica. Rev Bras Psiquiatr 2007;29:S19-S26.

30. Mello MT, Boscolo RA, Esteves AM, Tufik S. O exercício físico e os aspectos psicobiológicos. Rev Bras Med Esporte 2005;11:203-7.

31. Fitzpatrick TB. The validity and practicality of sun reative skin types I through VI. Arch Dermatol 1988;124:869-71.

32. Alchorne MMA, Abreu MAMM. Dermatologia na pele negra. An Bras Dermatol 2008;83:7-20.

33. Westerholf W. The relation between constitutional skin color and photosensitivity estimated from UV induced erythema and pigmentation dose-response curves. J Invest Dermatol 1990;94:812-6.

34. Zhao P, Zhu X, Liu Y, Wang B, Wang C, Burns FJ. Solar ultraviolet radiation and skin damage; an epidemiologic study among chinese population. Arch Environ Health 1998;53:405-9.

35. Haack RL, Horta BL, César JA. Queimadura solar em jovens: estudo de base populacional no Sul do Brasil. Rev Saúde Pública 2008;42:26-33.

36. Webb AR. Who, what, where and when-influences on cutaneous vitamin D synthesis. Prog Biophys Mol Biol 2006;92:17-25.

37. Murray JC, Madey DL, Pinnelli SR. Modern approaches to photoprotection. Dermatol Clin 2000;8:577-90.

38. Huncharek M, Kupelnick B. Use of topical sunscreens and the risk of malignant melanoma: a metaanalysis of 9067 patients from 11 case-control studies. Am J Public Health 2002;92:1173-7.

39. Whiteman DC, Brown RM, Purdie DM, Hughes MC. Melanocytic nevi in very young children: the role of phenotype, sun exposure and sun protection. J A Acad Dermatol 2005;52:40-7.

40. Mellman MF, Podesta L. Common medical problems in sports. Clinics Sports Med 1997;16:635-62.

41. Pharis DB, Teller C, Wolf JE. Cutaneous manifestations of sports participations. J A Acad Dermatol 1997;(3 S1):448-59.

42. Ambros-Rudolph CM, Hoffmann-Wellenhof R, Richtig E, Müller-Fürstner M, Soyer HP, Kerl H. Malignant melanoma in marathon runners. Arch Dermatol 2006;142:1471-4

43. Lim HW, Naylor M, Hönigsmann H, Gilchrest BA, Cooper K, Morison W, et al. American Academy of Dermatology Consensus Conference on UVA protection of sunscreens: summary and recommendations. J A Acad Dermatol 2001;44:505-8.

44. Bauer J, Büttner P, Wiecker TS, Luther H, Garbe C. Effect of sunscreen and clothing on the number of melanocytic nevi in 1812 german children attending day care. Am J Epidemiol 2005;161:620-7.

45. Talhari S, Lupi O. Fotoproteção e fotoprotetores. In: Câncer de pele. Rio de Janeiro: Médica e Cinetífica, 2001. pp 672-9.

46. Moehrle M, Heinrich L, Schmid A, Schmid A, Garbe C. Extrem UV exposure of professional cyclists. Dermatology 2000;201:44-5.

47. Moehrle M. Outdoor sports and skin cancer. Clin Dermatol 2008;26:12-5.

48. Hoffmann K, Kaspar K, Gambichler TA. In vitro and in vivo determination of the UV protection factor for lightweight cotton and viscose summer fabrics: a preliminary study. J A Acad Dermatol 2000;43:1009-16.

49. Steven Q. Reduction of ultraviolet transmission through cotton T-shirt fabrics with low ultraviolet protection by various laundering methods and dyeing: clinical implications. J A Acad Dermatol 2001;44:767-74.

50. Diário Oficial da União; Poder Executivo, 23 de agosto de 2002. Resolução RDC n.237, 22 de agosto de 2002.

51. Martins JEC. Estudo comparativo de diferentes veículos com fotoprotetores. An Bras Dermatol 1990;65:155-6.

52. Diffey BL. When should sunscreen be reapplied? J A Acad Dermatol 2001;45:882-5

53. Wright MW, Wright ST, Wagner RF. Mechanisms of sunscreen failure. J A Acad Dermatol 2001;44:781.

54. Costa FB, Weber MB. Avaliação dos hábitos de exposição ao sol e de fotoproteção dos universitários da Região Metropolitana de Porto Alegre, RS. An Bras Dermatol 2004;79:149-55.

55. Maier T, Korting HC. Sunscreens: which and what for? Skin Pharmacol Physiol 2005;18:253-62.

56. Crane LA, Schneider LS, Yohn JJ, Morelli JG, Plomer KD. "Block the sun, not the fun": Evaluation of a skin cancer prevention program for child care center. Am J Prev Med 1999;17:31-7. 